\title{
TUNABLE MIDDLE IR OPTICAL PARAMETRIC OSCILLATOR FOR SPECTROSCOPIC APPLICATIONS
}

\author{
M. Kaučikas ${ }^{\text {a }}$, Z. Kuprionis ${ }^{\text {b }}$, and V. Vaičikauskas ${ }^{\text {a }}$ \\ ${ }^{a}$ Institute of Physics, Laboratory of Nonlinear Optics and Spectroscopy, Savanoriu 231, LT-02300 Vilnius, Lithuania \\ E-mail: marius_kaucikas@yahoo.com \\ ${ }^{\mathrm{b}}$ UAB “EKSPLA", Savanoriu 231, LT-02300 Vilnius, Lithuania
}

Received 15 April 2005

\begin{abstract}
The operation of a middle infrared laser source based on the tandem optical parametric oscillator (OPO) was demonstrated. The first stage was based on the nonlinear KTP crystal and produced up to $45 \mathrm{~mJ}$ of $1.57 \mu \mathrm{m}$ radiation, while pumped by a commercial Q-switched Nd:YAG laser. The quality of signal beam was improved by using the unstable resonator. The $\mathrm{AgGaSe}_{2}$ crystal was used in the second stage OPO. Idler energies up to $1.2 \mathrm{~mJ}$ were generated in this stage within tuning range from 5 to $12 \mu \mathrm{m}$.
\end{abstract}

Keywords: optical parametric oscillator, frequency conversion, unstable resonators, lidar

PACS: $42.65 . \mathrm{Yj}$

\section{Introduction}

Differential absorption lidar (DIAL) is a powerful technique for remote detection of trace gas in the atmosphere [1]. Most of the devices reported in literature are based on either visible or near infrared light sources operating in the single line or tunable regime. While being well developed and commercially available, visible light sources cannot provide selective discrimination between different gases in atmosphere and are usually used only for relatively simple species, such as ozone, mercury, and others. Near infrared light sources operating in overtone or combination frequency region of multiatomic molecules are more suitable for spectroscopic applications. However, the absorption crosssection of most complex gases in near IR is much smaller than that in the mid-IR region, so-called fingerprint region. Consequently, to detect the same concentration of trace gas, much higher requirements for lasers and registration systems arise. Thus, the most appropriate choice of spectral region for DIAL applications would be the middle infrared region (wavelengths from 7 to $12 \mu \mathrm{m}$ ), because it corresponds to the region of fundamental vibration of most of the complex molecules and the atmospheric transmittance window.

The laser source suitable for DIAL applications in the atmosphere should meet several requirements, most important ones being sufficient energy, good beam quality, and continuous wavelength tuning in IR (6$12 \mu \mathrm{m})$ range, as well as reliability and stability. The optical parametric oscillator (OPO) is one of possible choices for these applications. The best developed and reliable OPO pump sources are Q-switched Nd:YAG lasers. The problem is that majority of nonlinear crystals suitable for mid-IR generation are not transparent at $1.064 \mu \mathrm{m}$ or do not have phase matching at this wavelength. The possible solution is a tandem scheme, when the Nd:YAG laser pumps near infrared OPO, and afterwards the output radiation of this stage is used to pump another cascade - a mid-IR OPO crystal. The divergence of the first OPO must be quite low to ensure efficient pumping of the second stage. The stable flatflat cavity usually produces very high beam divergence. Typically, a cavity length is several centimetres, and the beam diameter is several millimetres, when pumped with a few nanosecond pulses, making the OPO cavity highly multimode. Employment of unstable resonators allows getting low enough divergence of multimode nanosecond OPO. The advantages of using these modifications have been demonstrated recently [2-4].

This work represents novel results on a design of continuously tunable OPO devoted to wide purpose spectroscopic applications. We intend to incorporate this laser in DIAL systems for remote sensing of atmosphere. 


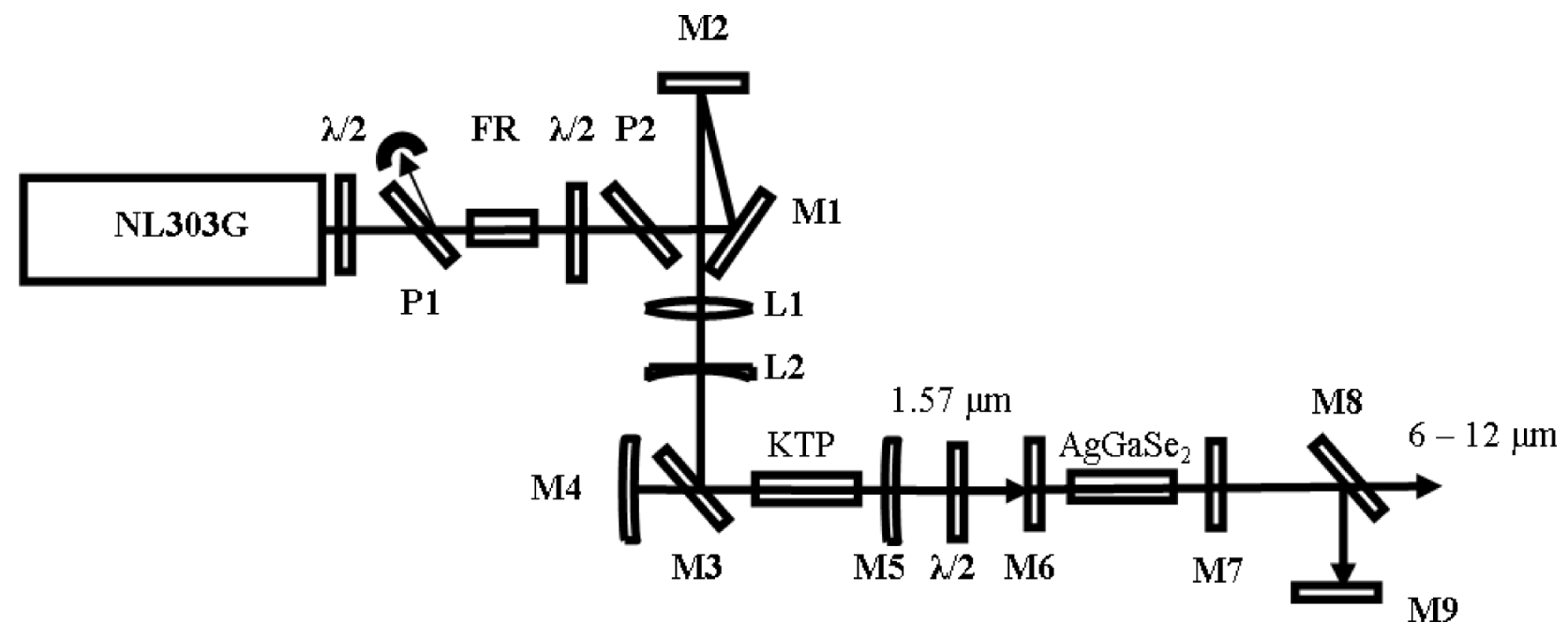

Fig. 1. Experimental set-up.

\section{Experimental set-up}

The experimental layout is shown in Fig. 1. The pump source was a commercial Nd:YAG actively Q-switched nanosecond laser (NL303G Ekspla Ltd). The pump laser produced up to $500 \mathrm{~mJ}$ of $1.064 \mu \mathrm{m}$ pulsed (duration 3-6 ns) radiation. The profile of the beam was hat-top.

The half-wave plates $\lambda / 2$, polarizers $\mathrm{P} 1, \mathrm{P} 2$, and Fresnel rotator FR were applied to avoid back reflections from OPO to the laser. The laser radiation was directed to the first OPO cavity by two steering mirrors M1 and M2. The beam diameter was compressed by a telescope consisting of lenses L1 and L2.

The first stage of OPO was based on the KTP $\left(5 \times 5 \times 25 \mathrm{~mm}^{3}\right)$ nonlinear crystal (EKSMA Com.). The crystal was anti-reflection coated for 1.064 and $1.57 \mu \mathrm{m}$ wavelengths and was cut at $\theta=90^{\circ}, \varphi=0^{\circ}$ (x-cut). This allowed noncritical phase matching (II type) at $1.57 \mu \mathrm{m}$ when pumped by $1.064 \mu$ m radiation.

The first stage OPO cavity was singly resonant for signal wave. Two sets of mirrors were used for the first stage OPO. The first set consisted of two flat mirrors. The rear mirror was highly reflective at $1.57 \mu \mathrm{m}$ and no special coatings for other wavelengths were used. The output coupler reflected all of the pump wavelength and was $50 \%$ reflective at signal radiation. The second set of mirrors consisted of two spherical mirrors. The radius of curvature of the concave rear mirror was $40 \mathrm{~cm}$ and that of the convex output coupler was $30 \mathrm{~cm}$. The latter was made as a zero meniscus lens. This choice of mirrors resulted in unstable positive-branch cavity with magnification factor $M=1.33$.

To yield a collimated beam, the length of cavity should be chosen according to the following expres- sion: $L=\left(R_{1}+R_{2}\right) / 2+L_{c}(1-1 / n)$ [3], where $R_{1}$ and $R_{2}$ are radii of curvature of cavity mirrors, $L_{c}$ and $n$ are the length and index of refraction of the nonlinear crystal.

The second stage of the tandem OPO system was based on the $\mathrm{AgGaSe}_{2}$ nonlinear crystal $(8 \times 10 \times$ $20 \mathrm{~mm}^{3}$ ). This crystal was cut for I type critical phase matching in 6-12 $\mu \mathrm{m}$ range, when pumped at $1.57 \mu \mathrm{m}$. The second stage OPO cavity was also singly resonant for signal wave $(1.8-2.2 \mu \mathrm{m})$. The cavity consisted of two flat mirrors: the rear mirror was highly transmitting at $1.57 \mu \mathrm{m}$ and highly reflective in $1.8-2.2 \mu \mathrm{m}$ range, whereas the output coupler reflected $50 \%$ of $1.8-2.2 \mu \mathrm{m}$ radiation and was highly transmitting in 6$12 \mu \mathrm{m}$ range. A dichroic mirror was used after this cavity to separate pump and signal waves from idler wave. The radiation reflected by separator could be returned back to the cavity to perform a second pass of pump radiation through the crystal using a mirror M9, as shown in Fig. 1.

\section{Results}

Primarily, the operation of the first stage of tandem OPO was investigated. The calculations using Sellmeier equations provided in [5] resulted in generation wavelength of $1.5711 \mu \mathrm{m}$, but our measurements showed that corresponding wavelength is $1.5722 \mu \mathrm{m}$. The measured spectral bandwidth of the signal radiation was $2.2 \mathrm{~cm}^{-1}$, or $0.54 \mathrm{~nm}$ (this value is close to the one provided in [6]). The difference between calculated and measured wavelengths could be explained by the different crystal growth techniques, as shown in [6]. Though KTP crystal was not tempera- 


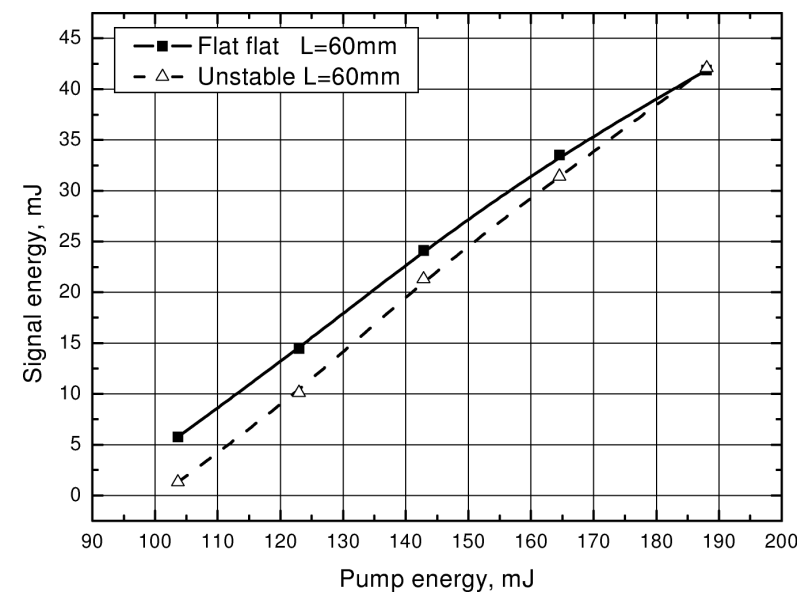

Fig. 2. Dependence of signal wave $(1.57 \mu \mathrm{m})$ energy in the first stage KTP OPO on pump energy. Two different sets of mirrors are used: stable flat-flat and unstable convex-concave $(M=1.33)$.

The length of the cavity is $60 \mathrm{~mm}$ in both cases.

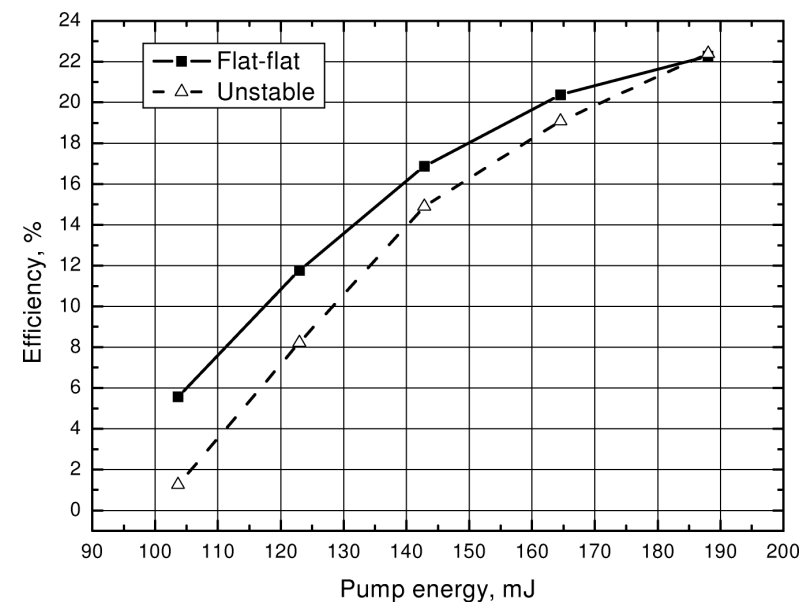

Fig. 3. Conversion to signal wave efficiency as a function of pump energy for flat-flat and unstable cavities.

ture stabilized, this should not result in such discrepancies. Our calculations show that temperature variation of $5^{\circ} \mathrm{C}$ produces less than $0.2 \mathrm{~nm}$ change in wavelength. Because there were no other means for measuring the divergence of the signal beam, we employed a moving knife method with $f=1000 \mathrm{~mm}$ lens according to [7]. The divergence was $4.5 \mathrm{mrad}$ in flat-flat cavity case and $3.2 \mathrm{mrad}$ in unstable cavity case. Further fine tuning of the set-up could produce much smaller divergence [2]. But the advantage of the unstable cavity is obvious, and an improvement in the divergence is enough to pump the second stage of tandem OPO system, as it is shown below.

The output energy and efficiency dependences on pump energy of the first stage are presented in Figs. 2 and 3. Threshold intensity was close to 100 $130 \mathrm{MW} / \mathrm{cm}^{2}$ for both flat-flat and unstable resonators.

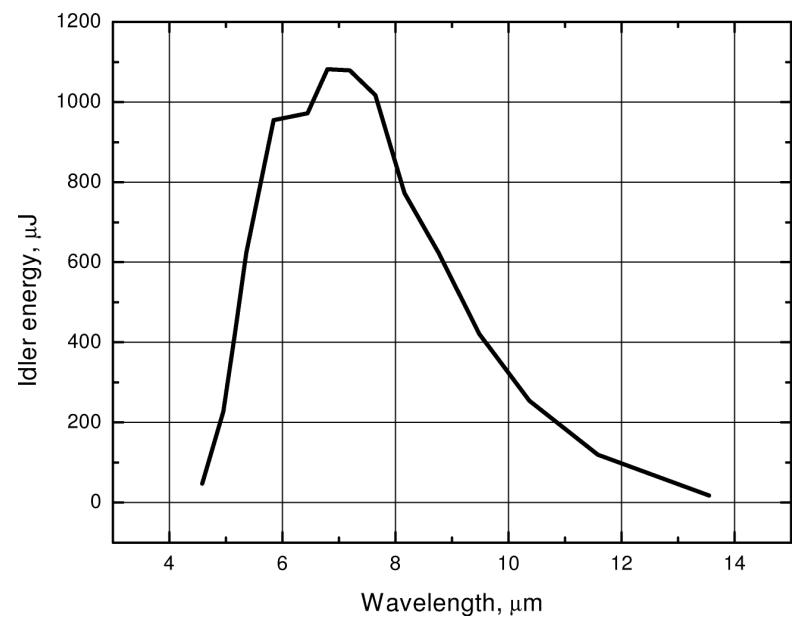

Fig. 4. Tuning curve of the second stage OPO.

As it can be seen in Fig. 2, signal energies just above threshold are higher in flat-flat case than in unstable one. As pump energy increases, the difference is becoming smaller and it vanishes at $190 \mathrm{~mJ}$ pump energies. A similar result was shown in [2]. This fact is also illustrated in Fig. 3, where the overall conversion efficiencies are shown. At higher pump energies the conversion efficiencies in both cases are almost similar - close to $22 \%$. This could be made more apparent by evaluating the slope efficiencies: flat-flat resonator gives $42 \%$, unstable $-48 \%$.

The tuning curve of the second stage is presented in Fig. 4. The calibration of wavelengths in this stage was made by means of polystyrene film absorption, as in [8]. We used absorption peaks at 6.245, 6.886, 6.699, and $9.725 \mu \mathrm{m}$. The agreement between calculations using Sellmeier equations from [9] and experimental data was well within experimental error. The threshold of oscillation was around $7 \mathrm{MW} / \mathrm{cm}^{2}$. All measurements of output energy and efficiency were performed with the second pump pass through the $\mathrm{AgGaSe}_{2}$ crystal. The limitation of the tuning to shorter wavelengths done by mirror coatings, and the fall-off at the long wavelength side is due to decreasing efficiency of the parametric interaction and the decrease of photon energy with wavelength. The decrease in efficiency can be clarified using Fig. 5, where the dependence of idler energy is depicted as a function of pump energy at different wavelengths. The calculated slope efficiency is given in the inset. The reduced energy around $6.4 \mu \mathrm{m}$ can be explained by water absorption in the air. The threshold is below the value stated before [2], but the slope efficiencies are lower, too. In contrast to that, the slope efficiencies of this OPO are higher than the ones stated in [8], but the threshold is higher, too. This is 


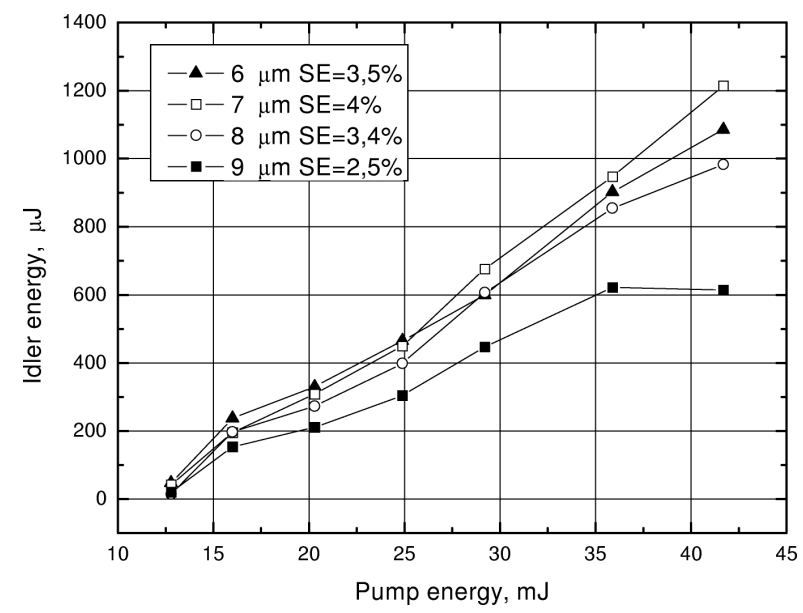

Fig. 5. Dependence of idler wave energy on pump $(1.57 \mu \mathrm{m})$ energy in the second stage $\mathrm{AgGaSe}_{2} \mathrm{OPO}$ for different wavelengths. $\mathrm{SE}$ is slope efficiency of conversion to idler wave for corresponding wavelengths.

determined by the choice of cavity mirrors and experimental set-up.

Finally, it is worth mentioning that no crystal damage was observed during all measurement period, while intensities were as high as $20 \mathrm{MW} / \mathrm{cm}^{2}$.

\section{Summary}

Generation of tunable mid-IR radiation using twostage tandem OPO was demonstrated. Tuning of wavelength in 5-12 $\mu \mathrm{m}$ region was demonstrated with pulse energies in $0.3-1 \mathrm{~mJ}$ range, reaching maximum energy of $1.2 \mathrm{~mJ}$ at $7 \mu \mathrm{m}$.

It was shown that tandem OPO with unstable resonator can provide most of the features needed for DIAL applications for pollution detection in the atmosphere.

Further improvement in conversion efficiencies in both stages could be achieved by optimizing beam diameters and cavity configurations.

\section{Acknowledgement}

The outlined experiment is a part of program "Infrared laser spectrometric remote atmospheric pollution sensing systems" (LISATNAS) supported by the Lithuanian State Science and Studies Foundation, contract No B-12/2003.

\section{References}

[1] P. Weibring, H. Edner, and S. Svanberg, Versatile mobile lidar system for environmental monitoring, Appl. Opt. 42(18), 3583-3594 (2003).

[2] J.N. Farmer, M.S. Bowers, and W.S. Scharpf, High brightness eye safe parametric oscillators using confocal unstable resonators, OSA TOPS on Advanced Solid-State Lasers 26, 567-570 (1999).

[3] S. Pearl, Y. Ehrlich, S. Fastig, and S. Rosenwaks, Nearly diffraction limited signal generated by a lower beam-quality pump in optical parametric oscillator, Appl. Opt. 42(6), 1048-1051 (2003).

[4] Y. Ehrlich et al., High brightness tunable tandem optical parametric oscillator at 8-12 $\mu \mathrm{m}$, CLEO 2003 Proceedings, TuB15 (2003).

[5] K. Kato and E. Takaoka, Sellmeier and thermo-optic dispersion formulas for KTP, Appl. Opt. 41(24) 50405044 (2002).

[6] M.V. Alampiev and O.F. Butiagin, Angular and temperature tuning characteristics of an optical parametric oscillator based on a $\mathrm{KTiOPO}_{4}$ crystal, Quantum Electronics 25(4), 345-349 (1998).

[7] International Standard ISO 11146, Lasers and laserrelated equipment - Test methods for laser beam parameters - Beam widths, divergence angle and beam propagation factor (01 06 1999).

[8] S. Chandra, T.H. Allik, G. Catella, R. Utano, and J.A. Hutchinson, Continuously tunable, 6-14 $\mu \mathrm{m}$ silver-gallium selenide optical parametric oscillator pumped at $1.57 \mu \mathrm{m}$, Appl. Phys. Lett. 74(5) 584-588 (1997)

[9] D.A. Roberts, Dispersion equations for nonlinear optical crystals: KDP, $\mathrm{AgGaSe}_{2}$ and $\mathrm{AgGaS}_{2}$, Appl. Opt. 35(24), 4677-4688 (1996). 


\title{
DERINAMAS VIDURINIOSIOS IR SRITIES PARAMETRINIS ŠVIESOS GENERATORIUS SPEKTROSKOPINIAMS TAIKYMAMS
}

\author{
M. Kaučikas ${ }^{\text {a }}$, Z. Kuprionis b , V. Vaičikauskas ${ }^{\text {a }}$ \\ ${ }^{a}$ Fizikos institutas, Vilnius, Lietuva \\ b UAB “EKSPLA", Vilnius, Lietuva
}

\section{Santrauka}

Aprašomas viduriniosios IR srities lazerinis šaltinis, kuri sudaro dvieju pakopu parametrinis šviesos generatorius (PŠG). Pirmoji pakopa, kur naudojamas KTP netiesinis kristalas, generavo iki $45 \mathrm{~mJ}$ spinduliuotès, kurios bangos ilgis $1,57 \mu \mathrm{m}$. Kaupinimui buvo naudojamas komercinis nanosekundinis Nd:YAG lazeris su aktyvia kokybės moduliacija ir lempiniu kaupinimu. Signalinès bangos pluošto kokybei pagerinti buvo naudojamas nestabilus rezonatorius. $\mathrm{AgGaSe}_{2}$ kristalas buvo panaudotas antrojoje pakopoje. Šios pakopos šalutinès bangos energija siekẻ 1,2 mJ, o bangos ilgis buvo derinamas 5-12 $\mu \mathrm{m}$ srityje. 